\title{
Reminiscence in children as a function of sex
}

\author{
LESLIE ZEGIOB \\ Arizona State University, Tempe, Arizona 85281 \\ and \\ R. B. PAYNE \\ University of Georgia, Athens, Georgia 30602
}

\begin{abstract}
Psychomotor reminiscence was measured in 40 children ( 20 males, 20 females) on two tasks, inverted alphabet printing and mirror tracking, administered in counterbalanced orders. The sexes reminisced alike on alphabet printing, as commonly found with young adults. On mirror tracking, however, males reminisced more than females, contrary to findings with young adults. These results in conjunction with others show that sex dominance in reminiscence tendencies depends upon task structure and that it undergoes reversal across pubescence.
\end{abstract}

Sex differences in recovery from the effects of massed practice seem well established for young adults on some tasks, but they are not found on others. For example, Buxton and Grant (1939) reported a difference in favor of females on rotary pursuit, while Archer and Bourne (1956) found no difference on inverted alphabet printing. Huang and Payne (1975) confirmed both findings, and they also demonstrated greater female reminiscence on a mirror tracking task. Thus, it appears that task structure poses one boundary condition that any conceptualization of sex differences must respect. Moreover, the differences reported were not related in any general way to initial aptitude, since $M>F$ on rotary pursuit while $\mathrm{F}>\mathrm{M}$ on mirror tracking and alphabet printing.

The empirical status of sex roles in reminiscence was further complicated by Horn's (1975) study of young children, in which males reminisced more than females on rotary pursuit. Although the conflict between Horn's results and those obtained from young adults might have been a function of differences in rotor speeds, a more exciting prospect may be that sex-related proclivities in reminiscence are not constant across the life span, at least for some tasks. Should this turn out to be the case, there is a further suggestion that events which comprise pubescence somehow rearrange sex-related recovery tendencies. This, in turn, leads directly to the question of pubescent alteration of differential sensitivities to the effects of massed practice.

The present study was conducted primarily for the purpose of seeking additional evidence relevant to the hypothesis that pubescent events may invert sex-related

Requests for reprints should be sent to R. B. Payne, Department of Psychology, University of Georgia, Athens, Georgia 30602. reminiscence tendencies, but it was also concerned with the question of whether inversion is some function of task structure. It was designed as a partial replication of Huang and Payne (1975), except that prepubescent children were employed as subjects.

\section{METHOD}

\section{Subjects}

The experimental sample consisted of 40 prepubescent children (20 males, 20 females) recruited through churches and schools in Athens, Georgia, and surrounding communities. Ages ranged from 96 to 123 months, males averaging 111 months and females 112 months.

\section{Tasks}

Inverted alphabet printing (Kimble, 1949) and mirror tracking (Payne \& Artley, 1972) comprised the task battery. The former task required subjects to print capital letters upside down so that they would appear correct when the paper was rotated $180 \mathrm{deg}$. The score was the number of letters printed correctly for each minute of practice. The latter task required subjects to use mirror vision in order to keep a stylus on a small silver target as it moved clockwise at $1 \mathrm{rpm}$ through a narrow star-shaped pathway. Time on target to the nearest $.01 \mathrm{sec}$ was recorded for each minute of practice.

\section{Procedure}

The 20 subjects within each sex group were assigned without bias to two task orders (AM, MA) with the constraint that the two order groups contained equal numbers. After instructions and demonstrations, each subject executed a sequence on each task consisting of a 3-min massed practice, 3-min rest, 3-min massed practice, 3-min rest, and 3-min massed practice. Transit time between tasks was also $3 \mathrm{~min}$.

\section{RESULTS}

\section{Reminiscence}

Each subject produced two reminiscence scores within each task. The magnitude of recovery was expressed as a simple difference between terminal prerest 
and initial postrest scores. Inasmuch as these values seemed rather small in comparison with those usually observed, and since there was no control group that would permit a partition of the interblock interval (IBI) gains into reminiscence and learning effects, a preliminary analysis of the differences between mean IBI gains and mean gains across preceding trials was made. Without exception, the IBI gains were significantly superior to the practice gains $(p<.05)$. Thus, significant amounts of classical reminiscence were inferred.

The reminiscence values within each task were subjected to a mixed-model variance analysis in which the main between-subjects effects were Orders and Sexes, while the main within-subjects effect was Reminiscence Periods. With regard to alphabet printing, no significant general Sex effect was found $(F<1)$, nor did the Sex variance depend upon the other independent variables of the study $(F<1)$. Mean reminiscence scores were 5.3 and 5.8 for males and females, respectively. It is clear, therefore, that the null results obtained from young adults were also characteristic of prepubescent children. With regard to mirror tracking, however, mean male reminiscence (2.39) was significantly greater than mean female reminiscence $(.63)$, as shown by $F(1,36)=$ $4.13, \mathrm{p}<.05$. This effect was orthogonal to all other effects in the analysis $(F<1)$, and it was contrary, like Horn's (1975) effect, to confirmed findings on young adults.

\section{Performance}

In view of the scarcity of definitive data on children, the results of the present study were also analyzed for sex differences in general performance trends. The 360 scores from each task were subjected to a mixed-model variance analysis in which Orders and Sexes comprised the main between-subjects effects, while Trial Blocks and Trials Within Blocks comprised the main withinsubjects effects. The subclass means are given in Tables 1 and 2 .

Table 1

Mean Letters Correctly Printed

\begin{tabular}{|c|c|c|c|c|c|c|}
\hline \multirow[b]{2}{*}{ Block } & \multirow[b]{2}{*}{ Trial } & \multicolumn{2}{|c|}{ AM Order } & \multicolumn{2}{|c|}{ MA Order } & \multirow{2}{*}{$\begin{array}{l}\text { Row } \\
\text { Means }\end{array}$} \\
\hline & & Male & Female & Male & Female & \\
\hline 1 & $\begin{array}{r}1 \\
2 \\
3 \\
1-3\end{array}$ & $\begin{array}{l}7.0 \\
6.2 \\
6.9 \\
6.7\end{array}$ & $\begin{array}{l}13.6 \\
13.7 \\
13.9 \\
13.7\end{array}$ & $\begin{array}{r}9.3 \\
7.4 \\
10.1 \\
8.9\end{array}$ & $\begin{array}{r}11.8 \\
9.9 \\
12.3 \\
11.3\end{array}$ & $\begin{array}{r}10.4 \\
9.3 \\
10.8 \\
10.2\end{array}$ \\
\hline 2 & $\begin{array}{r}1 \\
2 \\
3 \\
1-3\end{array}$ & $\begin{array}{r}11.2 \\
9.7 \\
11.6 \\
10.8\end{array}$ & $\begin{array}{l}17.1 \\
17.1 \\
17.8 \\
17.3\end{array}$ & $\begin{array}{l}11.8 \\
10.2 \\
12.0 \\
11.3\end{array}$ & $\begin{array}{l}16.2 \\
14.9 \\
15.3 \\
15.5\end{array}$ & $\begin{array}{l}14.1 \\
13.0 \\
14.2 \\
13.7\end{array}$ \\
\hline 3 & $\begin{array}{r}1 \\
2 \\
3 \\
1-3\end{array}$ & $\begin{array}{l}12.7 \\
11.0 \\
12.8 \\
12.2\end{array}$ & $\begin{array}{l}19.7 \\
18.3 \\
19.8 \\
19.3\end{array}$ & $\begin{array}{l}15.4 \\
13.9 \\
14.2 \\
14.5\end{array}$ & $\begin{array}{l}19.1 \\
18.5 \\
17.0 \\
18.2\end{array}$ & $\begin{array}{l}16.7 \\
15.4 \\
16.0 \\
16.1\end{array}$ \\
\hline Column & Means & 9.9 & 16.8 & 11.6 & 15.0 & 13.3 \\
\hline
\end{tabular}

Table 2

Mean Seconds on Target

\begin{tabular}{|c|c|c|c|c|c|c|}
\hline \multirow[b]{2}{*}{ Block } & \multirow[b]{2}{*}{ Trial } & \multicolumn{2}{|c|}{ AM Order } & \multicolumn{2}{|c|}{ MA Order } & \multirow{2}{*}{$\begin{array}{l}\text { Row } \\
\text { Means }\end{array}$} \\
\hline & & Male & Female & Male & Female & \\
\hline 1 & $\begin{array}{r}1 \\
2 \\
3 \\
1-3\end{array}$ & $\begin{array}{l}3.51 \\
4.78 \\
6.01 \\
4.77\end{array}$ & $\begin{array}{l}2.96 \\
1.59 \\
2.43 \\
2.33\end{array}$ & $\begin{array}{r}7.47 \\
8.01 \\
10.33 \\
8.60\end{array}$ & $\begin{array}{l}3.19 \\
3.41 \\
4.91 \\
3.84\end{array}$ & $\begin{array}{l}4.28 \\
4.45 \\
5.92 \\
4.89\end{array}$ \\
\hline 2 & $\begin{array}{r}1 \\
2 \\
3 \\
1-3\end{array}$ & $\begin{array}{l}8.41 \\
6.95 \\
8.35 \\
7.90\end{array}$ & $\begin{array}{l}3.27 \\
3.88 \\
3.97 \\
3.70\end{array}$ & $\begin{array}{l}11.95 \\
14.12 \\
13.40 \\
13.16\end{array}$ & $\begin{array}{l}5.36 \\
4.88 \\
6.52 \\
5.59\end{array}$ & $\begin{array}{l}7.25 \\
7.46 \\
8.06 \\
7.59\end{array}$ \\
\hline 3 & $\begin{array}{r}1 \\
2 \\
3 \\
1-3\end{array}$ & $\begin{array}{r}10.64 \\
7.71 \\
8.02 \\
8.79\end{array}$ & $\begin{array}{l}5.11 \\
4.75 \\
6.12 \\
5.32\end{array}$ & $\begin{array}{l}16.67 \\
17.89 \\
17.38 \\
17.31\end{array}$ & $\begin{array}{l}6.76 \\
6.98 \\
8.71 \\
7.46\end{array}$ & $\begin{array}{r}9.80 \\
9.33 \\
10.06 \\
9.72\end{array}$ \\
\hline Column & Means & 7.15 & 3.79 & 13.02 & 5.63 & 7.40 \\
\hline
\end{tabular}

With regard to alphabet printing, the significant sources of variation were Sexes $[F(1,36)=8.23$, $\mathrm{p}<.01]$, Blocks $[\mathrm{F}(2,72)=84.07, \mathrm{p}<.001]$, and Trials $[\mathrm{F}(2,72)=6.5, \mathrm{p}<.005]$, as in Huang and Payne (1975). As shown in Table 1, females were superior to males, as all investigators have found regardless of the age range examined. Moreover, the Sex effect was independent of all other effects $(\mathrm{F}<1)$.

With regard to mirror tracking, however, the outcomes were more complex than those found with young adults. One will recall that Huang and Payne (1975) found no general Sex effect, but rather an interaction of Sex by Trial effects in which males gained progressively over females as trials continued. By contrast, the present analysis revealed a general male dominance $[\mathrm{F}(1,36)=13.33, \mathrm{p}<.001]$, which grew progressively larger as practice blocks continued $[\mathrm{F}(2,72)=4.98$, $\mathrm{p}<.01]$. This interaction can be accounted for almost entirely by the sex difference in reminiscence, for when the reminiscence values were subtracted from the means of Blocks 2 and 3, the sex curves across blocks became essentially parallel and the interaction disappeared. In further contrast with young adult results, the present analysis also revealed a significant Orders effect $[F(1,36)=6.84, p<.025]$, which became progressively larger as a function of Blocks $[F(2,72)=3.59$, $\mathrm{p}<.05]$, and Trials $[\mathrm{F}(2,72)=3.31, \mathrm{p}<.05]$. When mirror tracking came first in the task sequence (Order MA), performance was substantially better than when it came last (Order AM). The interactions involving Orders (OB, OT) cannot be accounted for by the negligible Order differences in reminiscence.

\section{DISCUSSION}

Given the principal objectives of the study, the experimental outcomes seem clear and relatively simple. Taken together, and viewed in conjunction with comparable studies of young adults, they confirm beyond any reasonable doubt that sex differences in reminiscence depend upon task structure, as Huang and Payne (1975) surmised. The mirror tracking results 
alone, by virtue of their consistency with Horn's (1975) results on rotary pursuit and their contradiction of confirmed findings in young adults, lend strong support to the hypothesis that pubescence may reverse sex dominance in reminiscence tendencies. Even so, one cannot yet say with assurance that the biological events which comprise pubescence are themselves responsible for the reversal of these tendencies. The age range bracketed by Horn's study and the studies of young adults is characterized by a rapid differentiation of sex roles founded on cultural as well as biological factors, and neither set of determinants was ruled out by this study. Perhaps neither can be ruled out by any feasible control procedure, but one might approximate that objective by replicating the present study on subjects matched for age but dichotomized or stratified in terms of the onset of puberty.

Although the task specificity and reversibility of sex roles in reminiscence remain conceptually unclear, the fact of sex dominance per se poses no problem for prevailing reminiscence theory. Hull (1943) regarded reminiscence as an indicant of accumulated reactive inhibition $\left(I_{r}\right)$; Hull (1945) also provided for individual differences in terms of the empirical constants of representative equations. Within this context, the present results say that prepubescent males accumulated more $\mathbf{I}_{\mathbf{r}}$ during practice than did females of comparable status, while postpubescent males accumulated less $I_{r}$ than did females of comparable status. No complete escape from this obvious tautology seems possible, but there is nonetheless at least one transituational implication for which empirical content can be adduced, viz., that prepubescent males should profit more than females from practice distribution, while postpubescent females should profit more than males. Experimental evidence relevant to these projections is somewhat thin, but Payne (Note 1) found support for them in young adult subjects over roughly the first half of a 15-min practice sequence in mirror tracking, and Resick and Payne (Note 2) found marginal support in prepubescent subjects on rotary pursuit.

With regard to the performance trends revealed by the present study, the alphabet printing results were very similar to those from young adults except for lower achievement levels. Mirror tracking, on the other hand, revealed several differences between children and young adults, the most puzzling of which was the Order effect and its interaction with Block and Trial effects. One is tempted, of course, to invoke concepts of fatigue and/or boredom, to which children are notoriously susceptible. But the application of these concepts is inconsistent with the negligible Order effects in alphabet printing unless one postulates that the two tasks are unequally susceptible to such effects. Also, one might have expected Order differences in reminis- cence, but these were not found. Looking elsewhere for conceptual relief, one may think of negative transfer; but this, too, is inconsistent with alphabet printing results unless one invokes an assumption of asymmetry, and it is further weakened by the lack of comparable results from young adults. Finally, the Order effect may have reflected a sampling accident in which, despite the random assignment procedure, the AM group was populated with poorer learners. If so, this accident was not evident in the alphabet printing results. In short, none of these hypotheses survives the conventional tests of generality and parsimony. For the time being, therefore, the source of the Order effect must remain obscure.

\section{REFERENCE NOTES}

1. Payne, R. B. Sex and practice distribution effects. In preparation.

2. Resick, P. A., \& Payne, R. B. Sex and practice distribution effects in children. In preparation.

\section{REFERENCES}

ARCher, E. J., \& BouRNe, L. E., JR. Inverted-alphabet printing as a function of intertrial rest and sex. Journal of Experimental Psychology, 1956, 52, 322-328.

Buxton, C. E., \& Grant, D. A. Retroaction and gains in motor learning: II. Sex differences, and a further analysis of gains. Journal of Experimental Psychology, 1939, 25, 198-208.

Horn, P. W. Pursuit rotor speed, sex differences, and reminiscence in young children. Journal of Psychology, $1975,91,81-85$

Huang, K. L., \& Payne, R. B. Individual and sex differences in reminiscence. Memory \& Cognition, 1975, 3, 252-256.

Hull, C. L. Principles of behavior. New York: AppletonCentury-Crofts, 1943.

Hull, C. L. The place of innate individual and species differences in a natural-science theory of behavior. Psychological Review, 1945, 52, 55-60.

Kimble, G. A. An experimental test of a two-factor theory of inhibition. Journal of Experimental Psychology, 1949, 39, $15-23$.

Payne, R. B., \& Artley, C. W. Facilitation of psychomotor learning by classically differentiated supplementary feedback cues. Journal of Motor Behavior, 1972, 4, 47-55.

(Received for publication October 6, 1976.) 